\title{
Modelling the removal of lead from synthetic contaminated water by activated carbon from biomass of Diplocyclos Palmatus by RSM
}

\author{
Sivaprakasam A. and Venugopal T.* \\ Department of chemistry, GCE, Salem, Tamilnadu, India \\ Received: 25/10/2018, Accepted: 10/12/2018, Available online: 07/01/2019 \\ *to whom all correspondence should be addressed: e-mail: venugopalt@gcesalem.edu.in
}

https://doi.org/10.30955/gni.002929

\section{Abstract}

Diplocyclos Palmatus biomass activated carbon (DPAC) was used in this work to remove lead (II) ion from the synthetic wastewater. The DPAC was characterized for structural, surface morphology by SEM, whereas, the functional group was analyzed by FT-IR and XRD analysis. The Removal of $\mathrm{Pb}^{2+}$ was studied by batch method and various experimental parameters namely effect of $\mathrm{Pb}^{2+}$ concentration, contact time, effect of temperature; $\mathrm{pH}$ and effect of matrix were also studied. The Kinetic modelling studies showed that the adsorption of $\mathrm{Pb}^{2+}$ ion follows pseudo second order mechanism and Langmuir isotherm model was found to fit better for this study. The Thermodynamic study showed a negative value for $\Delta G$ indicating the process was spontaneous. Box Behnken Design using response surface methodology as DOE was carried out in this work. The RSM modelling was found to be successful in predicting the removal efficiency with $R^{2}$ greater than 0.95 .

Keywords: DPAC, hazardous $\mathrm{Pb}^{2+}$, adsorption isotherm, kinetic models, effect of matrix, response surface methodology.

\section{Introduction}

Many of the organic and inorganic pollutant such as dyes and heavy metals are one of the most dangers to our environment. Electroplating, Tannin, leather industry, battery manufacturing, smelting and mining are the major sources of the discharge of lead contaminated water (Azimi et al., 2017; Xu et al., 2017) to the environment. Among the trace metals, $\mathrm{Cu}^{2+}, \mathrm{Pb}^{2+}, \mathrm{Hg}^{2+}, \mathrm{Zn}^{2+}, \mathrm{Cd}^{2+}, \mathrm{Cr}^{2+}$, $\mathrm{Ni}^{2+}$ and $\mathrm{As}^{2+}$ have been considered as pollutants in the contaminated water. If the Lead was taken in small amount, it heavily injures the human body, affecting the central brain, kidney and liver. The central nervous system disorders causes coma and death. Also, the Lead poisoning in lower concentration may lead to anaemia and produce blue line on gums (Davies et al., 2016). There were two methods used for the removal of heavy metals viz., conventional and non conventional methods (Fu et al., 2016). The natural materials used for the elimination of trace metals from the contaminated water includes agricultural waste, coir pith, bone chair, wool, silk, and human hair (ATSDR, 2007). From the literature review, the activated carbon were readily available and cheap from the materials such as rice husk, fly ash, peanut husk and cow dung which were used for the removal of heavy metals from the contaminated water (Brown, 2012; Tong et al., 2000; Jia Guo et al., 2000). The Microwave radiation which was used to heat dielectric materials was also used to prepare activated carbon from various sources. The main advantage of using the microwave activation is that the treatment time would be considerably reduced; reduction in the energy consumption and also gases evolved in the treatment could also be reduced. Microwave activation can be done by both internal and volumetric heating for the preparation of activated carbon (Li et al., 2009). Therefore, microwave induced activation was rapid and effective at a lower temperature, resulting in the reduced treatment time (Venkatesh and Raghavan, 2004). Microwave heating technique have additional applications such as interior heating, higher heating rate, selective heating, controllable heating process. There was no direct contact with the heating source and materials and also it reduced the consumption of time (Liu et al., 2013). The RSM methodology was used to find out the best combination of various factors which control the removal of $\mathrm{Pb}^{2+}$ from the wastewater. RSM simplified the number of experiments and decreased the cost, reduced the experimental problems and needed less time compared to other statistical methods (Shahrak et al., 2016). Box Behnken Design (BBD) was used in this work for modelling and predicting the removal of $\mathrm{Pb}^{2+}$ ion by DPAC and the factors involved in the study were the concentration of $\mathrm{Pb}^{2+}$ ion, time of contact temperature and time. RSM was chosen as a compelling statistical and scientific approach so as to distinguish the efficiency of experimental method. Different parameters were applied in RSM at the same time to get a few numbers of experiments by the Design of Experiment (DOE). In the present study, the biomass of Diplocyclos Palmatus was 
used to prepare activated carbon as adsorbent to remove heavy metal particularly $\mathrm{Pb}^{2+}$ ion from synthetic water. The biomass of Diplocyclos Palmatus activated carbon (DPAC) has not been reported in the literatures to our best knowledge and this is a novel work.

\section{Experimental}

\subsection{Materials}

The biomass of Diplocyclos Palmatus was collected from shevaroy hills. The materials were dried for 3 days in air without exposure to sunlight and then crushed into fine size. The stems were then powered and sieved. The sieved samples were taken into chemical activation.

\subsection{Adsorbent preparation and characterization}

The sieved sample of Diplocyclos Palmatus biomass were mixed with $50 \%$ of phosphoric acid in 1:1 ratio and heated in the fume hood without stirring for 48 hours for complete dehydration. The liquid portion was then carefully decanted and the remaining solid portion was then taken in a stainless steel autoclave reactor. The autoclave reactor was heated in microwave oven with a constant $\mathrm{N}_{2}$ flow of $150 \mathrm{~m}^{3} / \mathrm{min}$ at $120^{\circ} \mathrm{C}$ for 2 hours. After the heating process the activated carbon was cooled under $\mathrm{N}_{2}$ atmosphere and then washed with distilled water to neutral $\mathrm{pH}$. The activated carbon (DPAC) was then dried at $100^{\circ} \mathrm{C}$ for 1 hour in air oven. DPAC and $\mathrm{Pb}^{2+}$ loaded DPAC surface morphology was carried out using the scanning electron microscope-EDS (Tescan Brno $62300)$ instrument. The FT-IR of both the samples were taken to characterize the functional group after and before the adsorption using Perkin Elmer spectrophotometer. The Atomic Absorption spectrophotometer (Systronic, India SL 163) was used to determine the concentration of the $\mathrm{Pb}^{2+}$ ion before and after adsorption in the solution. AAS analysis was done in triplicate and average results were used in this study to reduce the error in analysis.

\subsection{Synthesis of adsorbate solution}

$1.5984 \mathrm{~g}$ of $\mathrm{Pb}\left(\mathrm{NO}_{3}\right)_{2}$ was dissolved in $1000 \mathrm{~mL}$ of double distilled water to give a concentration of $1000 \mathrm{mg} \mathrm{L}^{-1}$ of $\mathrm{Pb}^{2+}$ ion in solution. From the $1000 \mathrm{mg} \mathrm{L}^{-1}$ stock solution, $10 \mathrm{~mL}$ was diluted to $100 \mathrm{~mL}$ which gives $100 \mathrm{mg} \mathrm{L}^{-1}$ (100 ppm) working solution. Experimental solutions of desired concentration were then obtained by successive dilutions. The initial $\mathrm{pH}$ measurements were carried out by $\mathrm{pH}$ instrument and were calibrated using the buffer solutions of $\mathrm{pH}$ values. The $\mathrm{pH}$ of the synthetic contaminated water was adjusted by the addition of diluted $\mathrm{HCl}$ and $\mathrm{NaOH}$ solutions.

\section{Characterization of the adsorbent}

\subsection{Surface morphology of the adsorbent}

The surface morphology of the adsorbent was characterized by SEM with EDS. The scanning electron microscope image of the adsorbent and $\mathrm{Pb}^{2+}$ loaded carbon were shown in Figure $1(a, c)$. The SEM images clearly differentiated the effect of the particle size of the DPAC. DPAC has excellent pore size, and the particles have high porosity, large surface area which gave a high solid surface, resulting in the efficiency of trace metals' removal from the contaminated water. From the Figure $1(b, d)$ the EDS image of DPAC before and after adsorption of the $\mathrm{Pb}^{2+}$ onto the DPAC were shown. The DPAC consisted of carbon, oxygen, silicon and traces of calcium. The Presence of silicon was common in the bark of the plants and in Figure $1(\mathrm{~d})$, the presence of the $\mathrm{Pb}^{2+}$ ion which was due to the adsorption of the metal onto the activated carbon was shown.

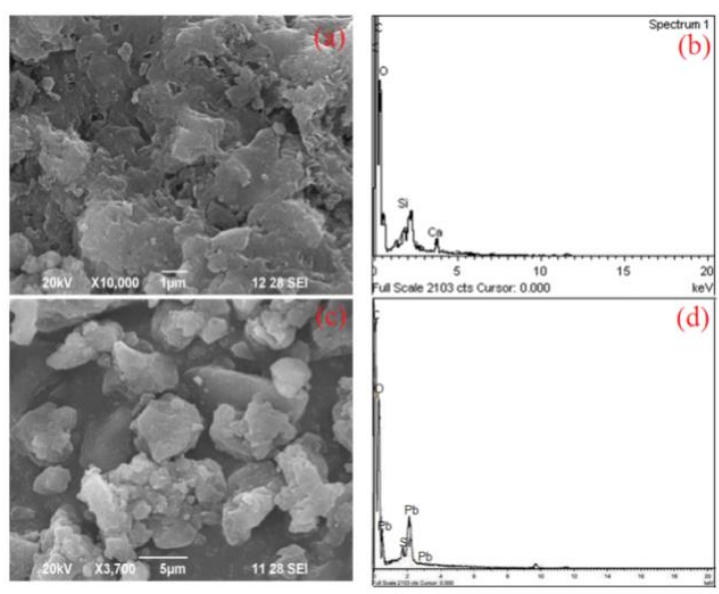

Figure 1. SEM-EDS images $(a, b)$ shows the pure biomass of the DPAC, $(c, d)$ show the after adsorption $\mathrm{Pb}^{2+}$ onto the biomass of the DPAC

\subsection{Functional group analysis}

Fourier transform infrared spectroscopy was used to investigate the functional group in the DPAC and metal ion adsorbed activated carbon which were shown in Figure $2(a, b)$. The spectrum of the DPAC before and after adsorption clearly showed a change in the nature of the peak, its intensity and the wave number. The FT-IR spectrum clearly suggested that the functional group in the activated carbon has played an important role in binding the $\mathrm{Pb}^{2+}$ ion in the solution. The spectra of DPAC showed a broad peak at around 3500 to $3000 \mathrm{~cm}^{-1}$ indicating the presence of $\mathrm{OH}$ group from the hydroxyl and carboxyl functional group. The peak around $2900 \mathrm{~cm}^{-1}$ suggested the presence of amine group. The broad peak around $1700 \mathrm{~cm}^{-1}$ suggested the presence of $\mathrm{C}=0$ group in the DPAC. The peak at $1300 \mathrm{~cm}^{-1}$ were assigned to methyl and methylene $\mathrm{C}-\mathrm{H}$ bending vibration.

XRD spectrum of DPAC was presented in Figure (3). From the XRD, it can be seen that there was no characteristic sharp peak which indicated that the carbon was amorphous in nature. A broad peak at $2 \theta=15-30^{\circ}$ was due to the partial graphitization of the carbon in the DPAC. It can be concluded from the XRD that the complete activation of the carbon has occurred with a very little crystallization still present in the DPAC.

\section{Batch adsorption method}

Batch studies were performed in a closed plastic container (250 $\mathrm{ml}$ capacity) with $100 \mathrm{ml}$ of adsorbate solution of 
different concentration ranging from $5 \mathrm{mg} \mathrm{L}^{-1}$ to $200 \mathrm{mg} \mathrm{L}^{-}$ ${ }^{1}$. Constant shaking of the solution was done using mechanical orbital shaker at the rate of $150 \mathrm{rpm}$. The ambient temperature was maintained throughout the experiment. The sample was shaken for 1 hour and then the sample was collected and filtered as discussed earlier.

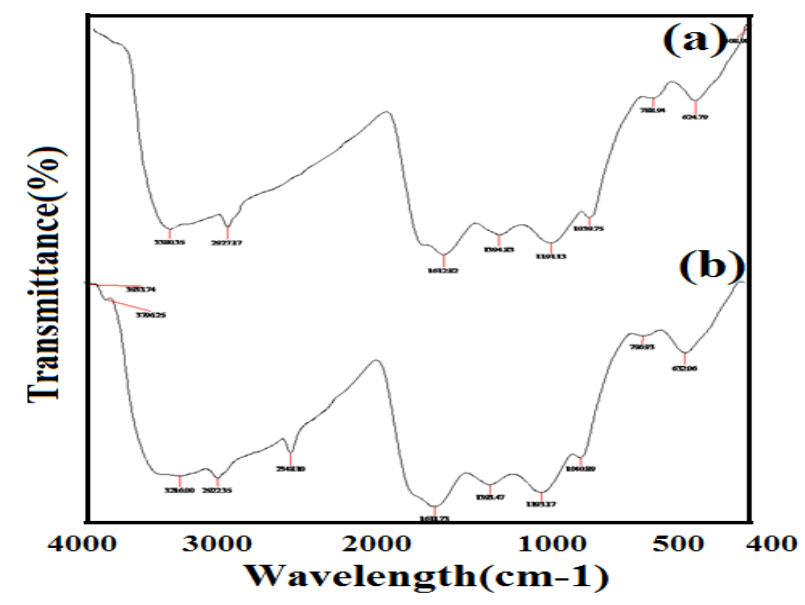

Figure 2. FT-IR image $(a, b)$ shows the before and after adsorption of $\mathrm{Pb}^{2+}$ onto the biomass of DPAC

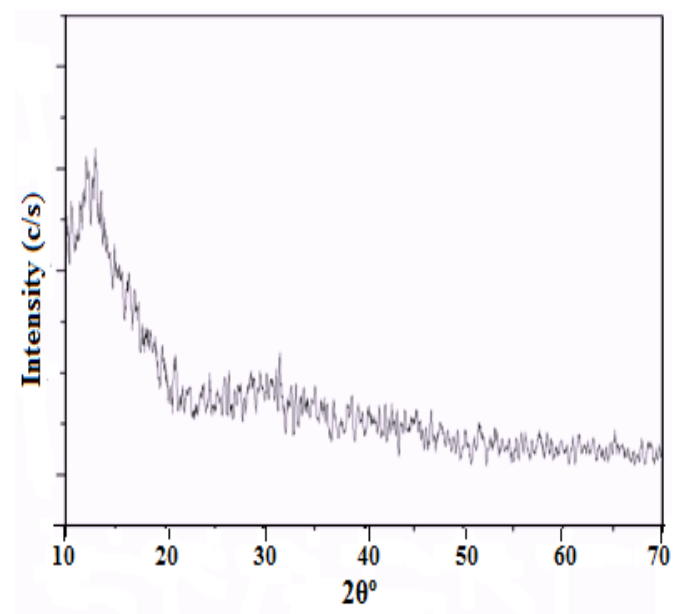

Figure 3. XRD image show the biomass of DPAC

The removal efficiency of the $\mathrm{Pb}^{2+}$ by the activated carbon was expressed by

Removalefficiency $(\%)=\frac{C_{0}-C_{e}}{C_{0}} \times 100$

Where $C_{o}$ and $C_{e}$ is the initial and equilibrium concentration in $\mathrm{mg} \mathrm{L}^{-1}$ of the Lead in water.

\section{Results and discussion}

\subsubsection{Effect of concentration}

The \% removal of the $\mathrm{Pb}^{2+}$ by the DPAC with various concentrations of lead ion was showed in Figure 4(a). With an increase in the concentration of $\mathrm{Pb}^{2+}$, it has been found that the removal \% decreases. The \% removal of the $\mathrm{Pb}^{2+}$ was fairly constant up to $60 \mathrm{mg} \mathrm{L}^{-1}$ with around $85 \%$ and decreased afterward. The decrease in the \% removal of the $\mathrm{Pb}^{2+}$ can be attributed to the fact that the surface of the adsorbent might have been fully saturated. The higher concentration of $\mathrm{Pb}^{2+}$ showed much less removal \% with $60 \mathrm{mg} \mathrm{L}^{-1}$ solution which showed a removal percentage of $85.76 \%$, then $100 \mathrm{mg} \mathrm{L}^{-1}$ solution gave a $60.92 \%$ removal and $200 \mathrm{mg} \mathrm{L}^{-1}$ solution gave $32.05 \%$ removal. In terms of the amount of $\mathrm{Pb}^{2+}$ adsorbed by the DPAC, the maximum amount of the $\mathrm{Pb}^{2+}$ adsorbed was found to be $60.92 \mathrm{mg} \mathrm{g}$ ${ }^{1}$. The maximum amount of the $\mathrm{Pb}^{2+}$ removal in terms of the mass of $\mathrm{Pb}^{2+}$ was shown by the solution of $200 \mathrm{mg} \mathrm{L}^{-1}$. The solution of $200 \mathrm{mg} \mathrm{L}^{-1}$ showed a maximum removal of $64.11 \mathrm{mg} \mathrm{g}^{-1}$. The decrease in the percentage of $\mathrm{Pb}^{2+}$ adsorption by $200 \mathrm{mg} \mathrm{L}^{-1}$ solution may be attributed to the fact that at equilibrium condition there might be more of the desorption taken place rather than adsorption. $60 \mathrm{mg}$ $\mathrm{L}^{-1}, 50 \mathrm{mg} \mathrm{L}^{-1}, 40 \mathrm{mg} \mathrm{L}^{-1}$ and $30 \mathrm{mg} \mathrm{L}^{-1}$ solution showed a maximum removal of $51.46 \mathrm{mg} \mathrm{g}^{-1}, 43 \mathrm{mg} \mathrm{g}^{-1}, 39.65 \mathrm{mg} \mathrm{g}^{-1}$ and $25.34 \mathrm{mg} \mathrm{g}^{-1}$ respectively. So with an increase in the concentration, it was seen that the surface coverage was increased and the removal reached a saturation point at around $60 \mathrm{mg} \mathrm{L}^{-1}$.

\subsubsection{Effect of time of contact}

The effect of the contact time on the percentage of removal of $\mathrm{Pb}^{2+}$ by the DPAC was also shown in Figure 4(a). The Time effect was studied by shaking the $\mathrm{Pb}^{2+}$ solution with activated carbon for a specified time interval. Various time intervals were chosen for determining the removal of the $\mathrm{Pb}^{2+}$ by the DPAC. 10,20 , $30,40,50$ and 60 minutes with the time interval of 10 minutes were taken up for the studies. After that 75, 90, 120 and 240 minutes were taken for the removal of $\mathrm{Pb}^{2+}$ by the DPAC. It is a known fact that with an increase in the contact time there would be an increase in the adsorption because with the higher time of contact there would be higher amount of adsorption taking place. DPAC showed a maximum removal of the $\mathrm{Pb}^{2+}$ occurs at an interval of 10 minutes itself, with a removal percentage of $62.4 \%$, which suggested that the adsorption takes place at quicker pace initially with many pore sites available in the activated carbon. With increase in the time the adsorption became slower, with $91.6 \%$ of the adsorption being completed at an interval of 30 minutes itself. The higher rate of adsorption showed the spontaneous effect of the adsorption at initial stages and equilibrium was reached after 30 minutes. With a further increase in the time, the percentage removal remains fairly constant. $\mathrm{Pb}^{2+}$ adsorption in the activated carbon attain equilibrium in 30 minutes and further increase in time of contact does not have any effect on the removal of the $\mathrm{Pb}^{2+}$ by the DPAC.

\subsubsection{Effect of temperature}

The temperature effect can be taken as the indicator to determine whether the adsorption was physical adsorption or chemical adsorption. In this study from Figure 4(c), it can be seen that the DPAC showed a decrease in adsorption of $\mathrm{Pb}^{2+}$ with an increase in temperature. This clearly showed that physical adsorption was the main process which controlled the mechanism of $\mathrm{Pb}^{2+}$ ion adsorption into an activated carbon. At lower temperature the maximum removal of the $\mathrm{Pb}^{2+}$ was found to be $98 \%$ for $10 \mathrm{mg} \mathrm{L}^{-1}$ solution. For the temperature 
$35^{\circ} \mathrm{C}$, the maximum removal was $97.5 \%$ for $10 \mathrm{mg} \mathrm{L}^{-1}$ solution and the removal efficiency drastically decreased with increase in concentration of the solution. The removal \% was $95.8 \%, 93.7 \%, 89 \%$ for the temperatures $45^{\circ} \mathrm{C}, 55^{\circ} \mathrm{C}, 65^{\circ} \mathrm{C}$ respectively. For all the temperatures, the higher concentration showed lower removal with minimum removal efficiency in $200 \mathrm{mg} \mathrm{L}^{-1}$ solution.
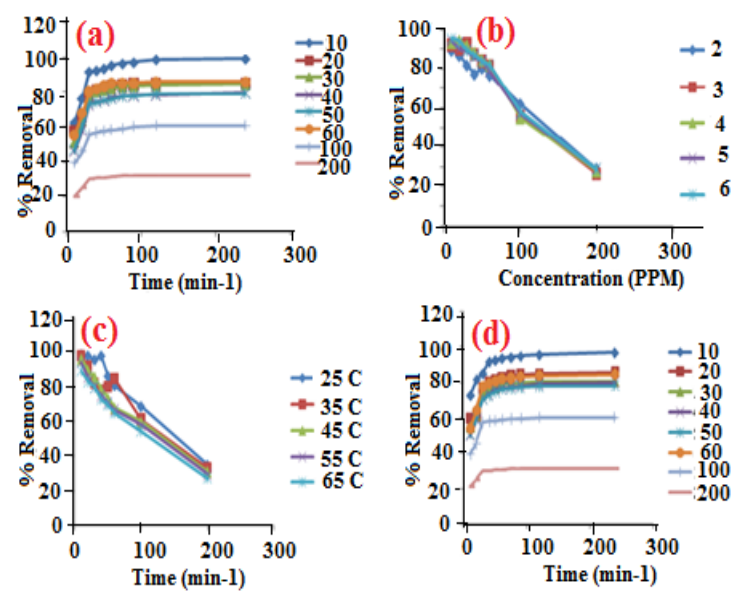

Figure 4. $(a, b, c, d)$ Removal $\%$ of $\mathrm{Pb}^{2+}$ by DPAC at different concentration, $\mathrm{pH}$, temperature, and contact time

\subsubsection{Effect of matrix}

Industrial wastewater may contain many other ions present along with the $\mathrm{Pb}^{2+}$ which may affect the adsorption of the $\mathrm{Pb}^{2+}$ in DPAC. So, in this study, the effect of other ions on the adsorption of the $\mathrm{Pb}^{2+}$ in DPAC at different concentrations of the $\mathrm{Pb}^{2+}$ prepared in $1 \%$ $\mathrm{Na}_{2} \mathrm{SO}_{4} 1 \% \mathrm{NaNO}_{3}$ and $1 \% \mathrm{NaCl}$ was studied. These salts were chosen because most of the industrial water was having a higher percentage of $\mathrm{SO}_{4}{ }^{2-}, \mathrm{NO}_{3}$, and $\mathrm{Cl}^{-}$. The removal \% was $95.7 \% 96.5 \%$, and $97.6 \%$ for $\mathrm{NaCl}$, $\mathrm{Na}_{2} \mathrm{SO}_{4}$ and $\mathrm{NaNO}_{3}$ respectively in $10 \mathrm{mgL}^{-1} \mathrm{~Pb}^{2+}$ ion concentration.

\subsubsection{Effect of $\mathrm{pH}$ on $\mathrm{Pb}$ (II) adsorption}

Aqueous phase $\mathrm{pH}$ governed the measurement of heavy metal and also the dissociation of active functional sites on the adsorbent. Hence, the metal adsorption was critically correlated with $\mathrm{pH}$. Different metals showed different $\mathrm{pH}$ optima for their adsorption and also varied with the surface functional group. The surface property of the activated carbon depends on the $\mathrm{pH}$ of the system which in turn determines the form in which lead (II) ion could exist. It was observed that the maximum adsorption occurred at $\mathrm{pH}$. Almost $96 \%$ of $\mathrm{Pb}^{2+}$ removal was observed at this $\mathrm{pH}$ at $100 \mathrm{mg} \mathrm{L}^{-1} \mathrm{~Pb}^{2+}$ concentration. The $\mathrm{pH}$ of the solution has a profound effect on the removal of the $\mathrm{Pb}^{2+}$ from the adsorbent. The existence of the particular oxidation state in the environment depends on the $\mathrm{pH}$ of the solution in which the particular metal was present. Some metal would get precipitated at certain $\mathrm{pH}$. For this study, the $\mathrm{pH}$ range was taken from 2 to 6 . This particular $\mathrm{pH}$ range was taken because at higher $(\mathrm{pH}>6) \mathrm{Pb}^{2+}$ would get precipitated as $\mathrm{Pb}(\mathrm{OH})_{2}$ and the removal of the $\mathrm{Pb}^{2+}$ was not possible.

\subsection{Thermodynamic study}

The standard Gibb's energy was evaluated by

$\Delta \mathrm{G}^{\circ}=-\mathrm{RT}_{\mathrm{InK}} \mathrm{c}_{\mathrm{c}}$

Where $R$ ideal gas constant $\left(R=8.314 \mathrm{~J} \mathrm{~mol}^{-1} \mathrm{~K}^{-1}\right)$ and $T$ is the temperature $(\mathrm{K})$.

The apparent equilibrium constant $\left(K_{c}\right)$ of the adsorption is defined as:

$\mathrm{Kc}=\frac{\mathrm{C}_{\text {ad.eq }}}{\mathrm{C}_{\text {eq }}}$

$\mathrm{C}_{\mathrm{ad}}$, equilibrium and $\mathrm{C}_{\mathrm{eq}}$ were the concentrations of $\mathrm{Pb}^{2+}$ on the adsorbent and at equilibrium respectively. The standard thermodynamic equilibrium constant $\left(K_{c}\right)$ can be used to determine the enthalpy and entropy of the system.

$$
\operatorname{lnK}_{\mathrm{c}}=-\frac{\Delta \mathrm{G}^{\circ}}{\mathrm{RT}}=-\frac{\Delta \mathrm{H}^{\circ}}{\mathrm{RT}}+\frac{\Delta \mathrm{S}^{\circ}}{\mathrm{RT}}
$$

The plot of $\ln K_{c}$ as a function of $1 / T$ yields on shown Figure 5 , a straight line from which $\Delta \mathrm{H}^{\circ}$ and $\Delta \mathrm{S}^{\circ}$ can be calculated from the slope and intercept, respectively and were presented in Table 1.

Table 1. Thermodynamic parameters of adsorbent at initial concentration of $50 \mathrm{mg} \mathrm{L}^{-1}$

\begin{tabular}{|c|c|c|c|}
\hline $\begin{array}{l}\text { Temp } \\
\text { (K) }\end{array}$ & $\begin{array}{c}\Delta \mathrm{G}^{\circ} \\
\left(\mathrm{K} \mathrm{J} \mathrm{mol}^{-1}\right)\end{array}$ & $\begin{array}{c}\Delta \mathrm{H}^{\circ} \\
\left(\mathrm{K} \mathrm{J} \mathrm{mol}{ }^{-1}\right)\end{array}$ & $\begin{array}{c}\Delta S^{\circ} \\
\left(\mathrm{K} \mathrm{J} \mathrm{mol} \mathrm{mo}^{-1} \mathrm{~K}^{-1}\right)\end{array}$ \\
\hline 308 & -3.52437 & \multirow{4}{*}{-10.7417} & \multirow{4}{*}{-25.5988} \\
\hline 318 & -2.67813 & & \\
\hline 328 & -2.40736 & & \\
\hline 338 & -2.31442 & & \\
\hline
\end{tabular}

From the Table $1-\Delta G^{\circ}$ at all temperatures were negative which indicated the spontaneous nature of the adsorption of $\mathrm{Pb}^{2+}$ in DPAC. The change of the standard free energy increased with increasing temperatures which indicated that a better adsorption was actually obtained at lower temperatures. Moreover, the standard free energy change for multilayer adsorption was more than $-20 \mathrm{~kJ}$ $\mathrm{mol}^{-1}$ and less than zero. It should be noted that the magnitude of $\Delta G^{\circ}$ values was in the range of multilayer adsorption. Negative $\Delta \mathrm{H}^{\circ}$ showed the exothermic nature of adsorption and negative $\Delta S^{\circ}$ showed the decreased randomness at the solid/solution interface during the adsorption process. This suggested that $\mathrm{Pb}^{2+}$ ions replace some water molecules from the solution which was previously adsorbed on the surface of the adsorbent. The values of $\Delta \mathrm{H}^{\circ}$ and $\Delta \mathrm{G}^{\circ}$ suggested that physisorption have taken place between the $\mathrm{Pb}^{2+}$ ions and DPAC at all temperature. These displaced molecules gained less translation entropy, thus allowing the prevalence of randomness in the system. Table 1 summarized the values of these thermodynamic properties. 


\subsection{Adsorption isotherms}

The successful illustration of the dynamic adsorptive separation of solute from solution in an adsorbent depends upon a good description of the equilibrium separation between the two phases. An adsorption isotherm was characterized by certain constant values, which expressed the surface properties and affinity of the adsorbent and can also be used to compare the adsorptive capacities of the adsorbent for different pollutants. In order to determine the mechanism of $\mathrm{Pb}^{2+}$ adsorption in the activated carbon and evaluate the relationship between adsorption temperatures, the experimental data was applied to the Langmuir and Freundlich isotherm equations. The adsorption isotherm constant $\left(Q_{0}, B, K, n\right)$ parameters were calculated by a linear regression form of the isotherm equations. The constant parameters and correlation coefficient $\left(R^{2}\right)$ were summarized in Table 2.

Langmuir isotherm model

$$
\frac{C_{e}}{q e}=\frac{1}{b K}+\frac{C_{e}}{Q_{0}}
$$

Where, $\mathrm{C}_{\mathrm{e}}$ is the concentration at equilibrium $\left(\mathrm{mg} \mathrm{L}^{-1}\right), \mathrm{q}_{\mathrm{e}}$ is the adsorption equilibrium $\left(\mathrm{mg} \mathrm{g}^{-1}\right), \mathrm{Q}_{0}$ and $\mathrm{K}$ is the Langmuir constants related to adsorption capacity and Energy of adsorption. Freundlich isotherm model

$$
\mathrm{q}_{\mathrm{e}}=\mathrm{K}_{\mathrm{f}} \mathrm{C}_{\mathrm{e}}^{\mathrm{n}}
$$

$\mathrm{K}_{\mathrm{f}}$ and $\mathrm{n}$ is the Freundlich model constants.

Table 2. Adsorption isotherm constants for $\mathrm{Pb}^{2+}$ onto the DPAC

\begin{tabular}{ccccccc}
\hline \multirow{2}{*}{ Temp (K) } & \multicolumn{3}{c}{ Langmuir Isotherm } & \multicolumn{3}{c}{ Freundlich Isotherm } \\
\cline { 2 - 7 } & $\mathbf{Q o}\left(\mathbf{m g ~ g}^{-1}\right)$ & $\mathbf{B ~ ( \mathbf { L ~ g } ^ { - 1 } )}$ & $\mathbf{R}^{\mathbf{2}}$ & $\mathbf{K} \mathbf{( \mathbf { ~ g } ^ { - 1 } )}$ & $\mathbf{n}$ & $\mathbf{R}^{\mathbf{2}}$ \\
\hline 308 & 71.42 & 0.01 & 0.99 & 0.97 & 0.32 & 0.91 \\
\hline 318 & 66.66 & 0.001 & 0.99 & 1.03 & 0.34 & 0.96 \\
\hline 328 & 62.51 & 0.021 & 0.99 & 1.10 & 0.37 & 0.94 \\
\hline 338 & 58.82 & 0.016 & 0.99 & 1.16 & 0.38 & 0.92 \\
\hline
\end{tabular}

Table 3. A comparison of the pseudo-first and second order model rate constants and theoretical (the) and experimental (exp) $\mathrm{q}_{\mathrm{e}}$

\begin{tabular}{|c|c|c|c|c|c|c|c|c|c|}
\hline \multirow{2}{*}{$\begin{array}{c}\text { Temp } \\
\left({ }^{0} \mathrm{C}\right)\end{array}$} & \multirow{2}{*}{$\begin{array}{c}C_{o} \\
\left(\mathrm{mg} \mathrm{L}^{-1}\right)\end{array}$} & \multirow{2}{*}{$\begin{array}{c}\operatorname{Exp} q_{e} \\
\left(\mathrm{mg} \mathrm{g}^{-1}\right)\end{array}$} & \multicolumn{3}{|c|}{ Pseudo-first order } & \multicolumn{4}{|c|}{ Pseudo-second order } \\
\hline & & & $k_{1}\left(\min ^{-1}\right)$ & the $q_{e}$ & $\mathbf{R}^{2}$ & $\begin{array}{c}\mathrm{K}\left(\mathrm{g} \mathrm{mg}^{-1}\right. \\
\left.\mathrm{min}^{-1}\right)\end{array}$ & the $q_{e}$ & $\begin{array}{c}\mathrm{h}\left(\mathrm{mg} \mathrm{g}^{-1}\right. \\
\left.\min ^{-1}\right)\end{array}$ & $\mathbf{R}^{2}$ \\
\hline \multirow[t]{4}{*}{35} & 10 & 9.750 & 0.082 & -27.77 & 0.95 & 0.0418 & 9.900 & 4.098 & 0.99 \\
\hline & 50 & 39.92 & 0.096 & -23.80 & 0.96 & 0.0055 & 41.66 & 9.708 & 0.99 \\
\hline & 100 & 60.87 & 0.032 & -71.42 & 0.36 & 0.0036 & 62.50 & 14.28 & 0.99 \\
\hline & 200 & 65.75 & 0.112 & -21.01 & 0.90 & 0.0034 & 71.42 & 17.54 & 0.99 \\
\hline \multirow[t]{4}{*}{45} & 10 & 9.580 & 0.055 & -41.66 & 0.97 & 0.0278 & 9.803 & 2.673 & 1 \\
\hline & 50 & 36.68 & 0.105 & -21.73 & 0.91 & 0.0073 & 38.46 & 10.86 & 0.99 \\
\hline & 100 & 59.43 & 0.108 & -21.27 & 0.94 & 0.0037 & 62.50 & 14.70 & 0.99 \\
\hline & 200 & 61.67 & 0.110 & -20.83 & 0.91 & 0.0062 & 60.60 & 24.39 & 0.99 \\
\hline \multirow[t]{4}{*}{55} & 10 & 9.370 & 0.089 & -25.64 & 0.97 & 0.0508 & 9.523 & 4.608 & 0.99 \\
\hline & 50 & 35.37 & 0.644 & -35.71 & 0.87 & 0.0082 & 37.03 & 11.36 & 0.99 \\
\hline & 100 & 57.82 & 0.112 & -20.40 & -0.04 & 0.0049 & 58.82 & 17.24 & 0.99 \\
\hline & 200 & 58.86 & 0.136 & -22.22 & 0.83 & 0.0095 & 62.50 & 23.25 & 0.99 \\
\hline \multirow[t]{4}{*}{65} & 10 & 8.900 & 0.736 & -31.25 & 0.86 & 0.0330 & 9.090 & 2.732 & 1 \\
\hline & 50 & 34.75 & 0.967 & -23.80 & 0.86 & 0.0087 & 35.71 & 11.11 & 0.99 \\
\hline & 100 & 54.26 & 0.113 & -22.72 & 0.87 & 0.0055 & 55.55 & 17.24 & 0.99 \\
\hline & 200 & 53.98 & 0.089 & -25.64 & 0.71 & 0.0076 & 54.05 & 22.22 & 0.99 \\
\hline
\end{tabular}
values were obtained at different initial $\mathrm{Pb}^{2+}$ concentrations and temperatures

As seen Table 2, Langmuir and Freundlich isotherms of $\mathrm{Pb}^{2+}$ adsorption on surface DPAC were found to be linear over the whole temperature range studied and $\mathrm{R}^{2}$ was extremely high. The value of $Q_{0}$ decreased with the increase in temperature, thereby confirming that the process was exothermic (Fountouli and Chrysikopoulos, 2018). It indicated that $\mathrm{Pb}^{2+}$ was favourably adsorbed by the DPAC. The values of $\mathrm{K}$ and $\mathrm{n}$ determined from the Freundlich model changed with the rise in temperature. The magnitude of $\mathrm{K}$ showed a low $\mathrm{Pb}^{2+}$ adsorptive capacity of the DPAC from aqueous solution at all temperature (K). Table 2 also indicated that $\mathrm{n}$ was less than 1.0 at all temperatures, indicating that $\mathrm{Pb}^{2+}$ was unfavourably adsorbed by DPAC.

\subsection{Adsorption kinetics}

Kinetics of the adsorption of lead in DPAC was monitored using pseudo-first order and pseudo-second order rate equation which can be represented

$\log \left(q_{e}-q_{t}\right)=\log q_{e}-\frac{k_{1}}{2.303} t$

Amount of the metal ion adsorbed at time $t$ was given by $\mathrm{q}_{\mathrm{t}}\left(\mathrm{mg} \mathrm{g}^{-1}\right)$ and first order rate constant was given by $\mathrm{k}_{1}$ 
$\left(\min ^{-1}\right)$. A straight line of $\log \left(q_{e}-q_{t}\right)$ vs $t$ suggested the applicability of this kinetic model. $q_{e}$ and $k_{1}$ could be calculated from the intercept and slope of the plot, respectively.

The pseudo-second order kinetic model ( $H_{0}$ equation) is expressed as

$\frac{1}{q_{t}}=\frac{1}{k_{2} q_{q}^{2}}+\frac{1}{q_{e}} t$

Where, $k_{2}$ is the rate constant of second order adsorbent. The plot $t / q_{t}$ versus $t$ should have been a straight line if pseudo-second-order kinetics was applicable whereas, the slope and intercept of the plot would give $q_{e}$ and $k_{2}$, respectively.

$h=K_{2} q_{e}^{2}$

\section{Where $\mathrm{h}$ is the initial sorption rate}

Table 3 provides the values of pseudo-first order rate constants $k_{1}$, pseudo-second order rate constants $k_{2}, h$, calculated equilibrium sorption capacity $\mathrm{q}_{e}$, the (theoretical) and experimental equilibrium sorption capacity $\mathrm{q}_{\mathrm{e}}$, exp (experimental) at various initial $\mathrm{Pb}^{2+}$ concentrations and temperatures. The validity of the kinetic models was tested by the magnitude of the regression coefficient $\mathrm{R}^{2}$ as given in Table 3 . It is important to note that for a pseudo-first order model, the correlation coefficient was always less than 0.97 , on the other hand, the application of a pseudo-second order model lead to much better regression coefficients, all values equal to or greater than 0.99. Moreover, the values of the $q_{e}$, estimated from the first order kinetic model gave significantly different values compared to exp $\mathrm{q}_{\mathrm{e}}$ values and were found to be fairly lower. However, in pseudo-second order kinetic model, the $\mathrm{q}_{\mathrm{e}}$ values (the) were very close to $\mathrm{q}_{\mathrm{e}}$ values (exp) at various initial $\mathrm{Pb}^{2+}$ concentrations and temperatures. The pseudo-second order model has been found to be extensively applied for studying physiochemical interaction in numerous environmental adsorption studies (Sotirelis and Chrysikopoulos, 2015; Vasiliadou and Chrysikopoulos, 2011; Fountouli and Chrysikopoulos, 2018). For the pseudo-second order model, the rate constant decreased with an increase of initial $\mathrm{Pb}^{2+}$ concentration, while the initial sorption rate, $h$, generally increased with an increase of initial $\mathrm{Pb}^{2+}$ concentration at all temperatures. Further, the values of correlation coefficients $\left(R^{2}\right)$ of pseudo-first order model were lower than those of a pseudo-second order model for all the sorption processes indicating that pseudo-second order model was better obeyed than pseudo- first order model equation. The analysis of kinetic data by other researchers showed that the pseudo-second order rate equation was a reasonably good fit for $\mathrm{Pb}^{2+}$ adsorption (Kose et al., 2011; Niu et al., 2016). The pseudo-second order equation provided the best correlation $\left(R^{2}=0.99\right)$ for all of the sorption process.

\subsection{Response surface methodology (RSM)}

RSM is widely used for predicting and optimizing the condition for the removal of $\mathrm{Pb}^{2+}$ from the wastewater.
For the removal of heavy metal from wastewater, various factors like concentration of the $\mathrm{Pb}^{2+}$ ion, amount of adsorbent, temperature, $\mathrm{pH}$ and time of contact influence the process. It was hard to determine the optimal condition for each variable (factor) for the removal of $\mathrm{Pb}^{2+}$ since it would involve large number of experiments. But, RSM was simplified by the Design of Experiment (DOE) and if these experiments were carried out, the response would be used for determining the best combination of factor for the optimal removal of the heavy metal. In this study, Box Behnken Design (BBD) was used (Table 4). The removal of $\mathrm{pb}^{2+}$ from the wastewater was strongly dependant on the $\mathrm{pH}$. In alkaline condition, $\mathrm{pH}$ greater than 7 , lead got precipitated from the solution hence its removal from the water was not possible at higher $\mathrm{pH}$. The Central Composite Design (CCD) would involve the use of extreme condition (upper and lower limits) of $\mathrm{pH}$ and hence, CCD was not used in this work. The number of variables used in this work was 4 viz., concentration of the lead, contact time, $\mathrm{pH}$ and temperature. The Total Number of Experiments (TNE) used in this work was 27 which is according to the equation (10)

TNE $=2 k(k-1)+C_{0}$

Where, $k=4$ is the number of variable and $C_{0}=3$ is the number of central point in this work. Minitab 17 was used in this study for RSM study and a quadratic equation was generated according to the equation (11)

$Y=\beta_{0}+\beta_{1} X_{1}+\beta_{2} X_{2}+\beta_{3} X_{3}+\beta_{4} X_{4}+\beta_{11} X_{1}^{2}+\beta_{22} X_{2}^{2}+$

$\beta_{33} X_{3}^{2}+\beta_{44} X_{4}^{2}+\beta_{12} X_{1} X_{2}+\beta_{23} X_{2} X_{3}$

$+\beta_{34} X_{3} X_{4}+\beta_{41} X_{1} X_{4}+\beta_{13} X_{1} X_{3}+\beta_{24} X_{2} X_{4}$

$X_{1}, X_{2}, X_{3}$ and $X_{4}$ are the initial concentrations of lead $\left(X_{1}\right)$, time of contact $\left(X_{2}\right)$, temperature $\left(X_{3}\right)$ and $\mathrm{pH}\left(X_{4}\right)$ of the solution respectively. $\beta_{0}$ is a constant and $\beta^{\text {'s }}$ is the coefficient of the linear, quadratic and crossed variables.

Table 4. The values of variable for the BBD design of experiment

\begin{tabular}{ccccc}
\hline Parameters & Code & $\mathbf{- 1}$ & $\mathbf{0}$ & $\mathbf{+ 1}$ \\
\hline Concentration of dye & $\mathrm{X}_{1}$ & 30 & 35 & 40 \\
\hline Time of contact & $\mathrm{X}_{2}$ & 70 & 87.5 & 100 \\
\hline Temperature & $\mathrm{X}_{3}$ & 40 & 45 & 50 \\
\hline $\mathrm{pH}$ & $\mathrm{X}_{4}$ & 5.0 & 5.5 & 6.0 \\
\hline
\end{tabular}

Batch run were carried out to determine the interaction between the $X_{1}, X_{2}, X_{3}$, and $X_{4}$. The results of the experiments for the removal efficiency were summarized in Table 5. The results were used to develop a regression model and a second order polynomial equation was developed (eq-11) (Amini and Younesi, 2009; Azila et al., 2008; Bingol et al., 2012). The 27 experiments were carried out and the summary of the lack of fit and analysis of variance (ANNOVA) was presented in Table 6.

$$
\begin{aligned}
& \% \text { Removal }=87+6.62 X_{1}-2.73 X_{2} 2.54 X_{3} \\
& 23.2 \mathrm{X}_{4}-0.044 \mathrm{X}_{1} \mathrm{X}_{1}+0.017 \mathrm{X}_{2} \mathrm{X}_{2}- \\
& 0.02 x_{3} x_{3}+2.76 x_{4} x_{4}-0.0093 x_{1} x_{2}+0.0082 x_{1} x_{3}- \\
& 0.702 x_{1} x_{4}+0.0115 x_{2} x_{3}-0.055 x_{2} x_{4}+0.62 x_{3} x_{4}
\end{aligned}
$$

Equation 12 can be used to predict the removal \% of the $\mathrm{Pb}^{2+}$ from the waste water by DPAC. The sign of the 
coefficient in each variable indicated whether the factor was synergistic or antagonist. The positive values of the factor indicated the synergistic effect and a negative sign of the coefficient which means it has antagonist effect. The suitability of model can be inferred by the Fishcer's ' $\mathrm{F}$ ' test and student ' $\mathrm{t}$ ' test. The ' $\mathrm{t}$ ' test was used to determine the value of $P$ (level of significance). In this work, $F$ value was found to be 16.40 which was high indicating that the model was suitable for the removal of $\mathrm{Pb}^{2+}$ by DPAC. $\mathrm{P}<0.0001$ confirmed that the BBD model fits the experimental data and suitability of the statistical analysis for this work. The $P$ value can also be used to determine the level of significance of each variable and among the variables. In this work $5 \%$ level of significance was followed. The Linear, quadratic and interaction effect was found to be significant when $p<$ 0.05 . On comparing the values of lack of fit (2.165) and $P(0.008)$ (lesser than 0.05) indicated that the lack of fit was insignificant. The non significant lack of fit indicated a good predictability of the data in this study. Correlation coefficient $\left(R^{2}\right)$ was found to be high $\left(R^{2}=0.97\right)$ indicating that prediction through this model has a very low error. The $R^{2}$ indicated that the model showed only $3 \%$ error which was within the experimental limit. The $F$ statistics for linear and quadratic interaction were higher indicating that the data of each component was significant for the testing hypothesis on the factor in the model. The associated "P" value for these interactions was found to be lesser than 0.05 confirming their significance to the modelling. The 2 way interaction showed higher " $P$ " value (0.108) suggesting that it has less significance to the model, but it was interesting to note that out of six, 2 two way interaction showed higher significance with $P$ value less than 0.05 . So it can be concluded that four 2 way interaction viz., $X_{1} X_{2}, X_{1} X_{3}, X_{2}$ $X_{3}$ and $X_{2} X_{4}$ does not show any significance indicating that these factors does not depend on one another and hence were independent to each other. Table 6 shows that $X_{1}$, $X_{2}, X_{3}$ and $X_{4}$ has $P$ values less than 0.05 were significant. $\mathrm{X}_{2}{ }^{2}$ was found to be significant in the quadratic single factor and in the quadratic two factor interaction, $X_{1} X_{4}$ and $X_{3} X_{4}$ were found to have $P<0.05$ showing significance to the model.

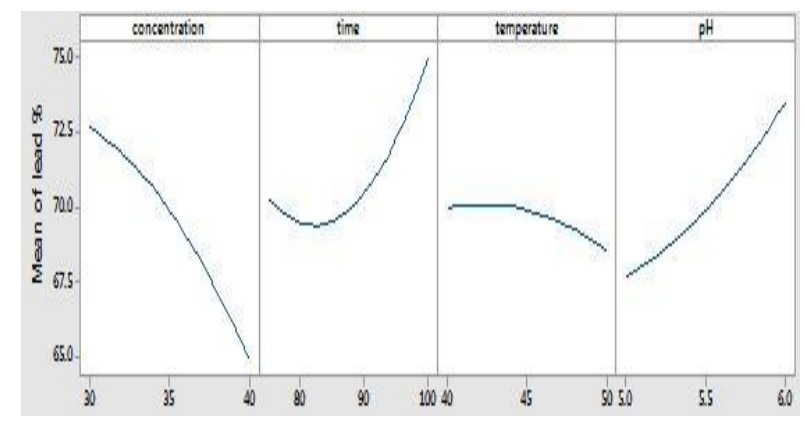

Figure 5. Main effect plot of various factors on the removal of the $\mathrm{Pb}^{2+}$ by the DPAC
Table 5. Summarize the removal efficiency of the $\mathrm{Pb}^{2+}$

\begin{tabular}{|c|c|c|c|c|c|}
\hline Exp. No & $x_{1}$ & $x_{2}$ & $x_{3}$ & $X_{4}$ & $\%$ removal \\
\hline 1 & 35 & 87.5 & 45 & 5.5 & 69.95 \\
\hline 2 & 30 & 100 & 45 & 5.5 & 77.34 \\
\hline 3 & 30 & 87.5 & 50 & 5.5 & 70.87 \\
\hline 4 & 35 & 87.5 & 50 & 5 & 64.67 \\
\hline 5 & 40 & 100 & 45 & 5.5 & 68.89 \\
\hline 6 & 35 & 87.5 & 40 & 6 & 71.80 \\
\hline 7 & 40 & 87.5 & 45 & 5 & 63.79 \\
\hline 8 & 40 & 87.5 & 50 & 5.5 & 63.89 \\
\hline 9 & 35 & 75 & 45 & 6 & 74.56 \\
\hline 10 & 35 & 100 & 45 & 5 & 73.68 \\
\hline 11 & 35 & 87.5 & 50 & 6 & 74.66 \\
\hline 12 & 35 & 100 & 45 & 6 & 77.98 \\
\hline 13 & 35 & 87.5 & 45 & 5.5 & 69.74 \\
\hline 14 & 30 & 75 & 45 & 5.5 & 72.67 \\
\hline 15 & 35 & 100 & 40 & 5.5 & 74.89 \\
\hline 16 & 35 & 87.5 & 40 & 5 & 68.05 \\
\hline 17 & 35 & 100 & 50 & 5.5 & 74.87 \\
\hline 18 & 40 & 87.5 & 45 & 6 & 65.99 \\
\hline 19 & 30 & 87.5 & 45 & 5 & 68.76 \\
\hline 20 & 40 & 87.5 & 40 & 5.5 & 65.98 \\
\hline 21 & 30 & 87.5 & 40 & 5.5 & 73.78 \\
\hline 22 & 35 & 75 & 45 & 5 & 68.88 \\
\hline 23 & 35 & 75 & 40 & 5.5 & 69.78 \\
\hline 24 & 30 & 87.5 & 45 & 6 & 77.98 \\
\hline 25 & 35 & 75 & 50 & 5.5 & 66.87 \\
\hline 26 & 40 & 75 & 45 & 5.5 & 66.56 \\
\hline 27 & 35 & 87.5 & 45 & 5.5 & 69.98 \\
\hline
\end{tabular}



Figure 6. $(\mathrm{a}, \mathrm{b})$ Counter and surface plot of the $\% \mathrm{~Pb}^{2+}, \mathrm{pH} \mathrm{Vs}$ Concentration, (c, d) Counter and surface plot of the $\% \mathrm{~Pb}^{2+}, \mathrm{pH}$ Vs Temperature

The contour plot and surface plot of the 2-way interaction which showed high significance was shown in the Figure 6. The $\mathrm{pH}$ was one of the most important factors for the adsorption of the lead in the activated carbon. From the contour plots, it can be inferred that lower $\mathrm{pH}$ resulted in lower removal of the $\mathrm{Pb}^{2+}$ with temperature and concentration. This can be attributed to the fact that at lower $\mathrm{pH}$ the functional group in the DPAC would be 
protonated resulting in the repulsion between the adsorbent and the metal.

Table 6. Summary of analysis of variance (ANNOVA)

\begin{tabular}{cccccc}
\hline Source & DF & Adj SS & Adj MS & $\begin{array}{c}\text { F- } \\
\text { Value }\end{array}$ & $\begin{array}{c}\text { P- } \\
\text { Value }\end{array}$ \\
\hline Model & 14 & 414.85 & 29.63 & 16.40 & 0.00 \\
\hline Linear & 4 & 327.55 & 81.88 & 45.32 & 0.00 \\
\hline $\mathrm{X}_{1}$ & 1 & 156.25 & 156.2 & 86.48 & 0.00 \\
\hline $\mathrm{X}_{2}$ & 1 & 60.211 & 60.21 & 33.32 & 0.00 \\
\hline $\mathrm{X}_{3}$ & 1 & 8.3350 & 8.335 & 4.61 & 0.05 \\
\hline $\mathrm{X}_{4}$ & 1 & 102.75 & 102.7 & 56.87 & 0.00 \\
\hline Square & 4 & 62.338 & 15.58 & 8.63 & 0.00 \\
\hline $\mathrm{X}_{1} \mathrm{X}_{1}$ & 1 & 6.3720 & 6.372 & 3.53 & 0.08 \\
\hline $\mathrm{X}_{2} \mathrm{X}_{2}$ & 1 & 33.991 & 33.99 & 18.81 & 0.00 \\
\hline $\mathrm{X}_{3} \mathrm{X}_{3}$ & 1 & 1.1300 & 1.130 & 0.63 & 0.44 \\
\hline $\mathrm{X}_{4} \mathrm{X}_{4}$ & 1 & 2.5050 & 2.505 & 1.39 & 0.26 \\
\hline $2-\mathrm{Way}_{\text {Way }}$ & 6 & 24.969 & 4.162 & 2.30 & 0.10 \\
Interaction & & & & & \\
\hline $\mathrm{X}_{1} \mathrm{X}_{2}$ & 1 & 0.1980 & 0.198 & 0.11 & 0.74 \\
\hline $\mathrm{X}_{1} \mathrm{X}_{3}$ & 1 & 0.1320 & 0.132 & 0.07 & 0.79 \\
\hline $\mathrm{X}_{1} \mathrm{X}_{4}$ & 1 & 12.327 & 12.32 & 6.82 & 0.02 \\
\hline $\mathrm{X}_{2} \mathrm{X}_{3}$ & 1 & 2.0880 & 2.088 & 1.16 & 0.30 \\
\hline $\mathrm{X}_{2} \mathrm{X}_{4}$ & 1 & 0.4760 & 0.476 & 0.26 & 0.61 \\
\hline $\mathrm{X}_{3} \mathrm{X}_{4}$ & 1 & 9.7480 & 9.748 & 5.40 & 0.03 \\
\hline Error & 12 & 21.683 & 1.807 & - & - \\
\hline Lack-of-Fit & 10 & 21.649 & 2.165 & 128.7 & 0.008 \\
\hline Pure Error & 2 & 0.0340 & 0.01 & - & - \\
\hline Total & 26 & 436.54 & - & - & - \\
\hline
\end{tabular}

The optimal condition for the removal of $\mathrm{Pb}^{2+}$ from the RSM was as follows: $X_{1}=30 \mathrm{mg} \mathrm{L}^{-1} ; X_{2}=100 \mathrm{~min} ; \mathrm{X}_{3}=50^{\circ} \mathrm{C}$; $X_{4}=6$; Predicted $=84.05 \%$; Experiment $=83.12 \%$

\section{Conclusion}

A reactor can be designed to study the removal of the $\mathrm{Pb}^{2+}$ from industrial wastewater since the time required for the removal was minimum. The $\mathrm{pH}$ has profound effect on the removal of the $\mathrm{Pb}^{2+}$ from the solution. It was found that slightly alkaline $\mathrm{pH}$ was the ideal condition for the removal of the $\mathrm{Pb}^{2+}$ from the water by DPAC. The Matrix effect was found to be minimum in the removal of the $\mathrm{Pb}^{2+}$ from the surface modified DPAC. Langmuir model provides better correlation coefficient $\left(R^{2}=0.99\right)$ than the Freundlich $\left(R^{2}=\right.$ 0.96) model. The results indicated that the pseudosecond order equation provided the best $R^{2}$ for the adsorption. These results demonstrated the great potential of plant residues, as low-cost heavy metal adsorbed adsorbent. The heavy metal removal technique using such adsorbent would be an effective method for the economic treatment of wastewater. RSM model was successfully applied in this study and was found to predict the adsorption pretty accurately.

\section{References}

Abechi S.E., Gimba C.E. and Uzairu A., et al. (2013), Preparation and characterization of activated carbon from palm kernel shell by chemical activation, Research Journal of Chemical Science, 3(1), 54-61.

Adewoye L.T., Mustapha S.I. and Adeniyi A.G., et al. (2017), optimization of nickel (ii) and chromium (iii) removal from contaminated water using sorghum bicolor Nigerian Journal of Technology, 36, 960-972.

Agency for Toxic Substances and Disease Registry (ATSDR) (2007), Toxicological Profile for Lead, US Depart. of Health and Human Services, Atlanta.

Amini M. and Younesi H. (2009), Biosorption of Cd(II) Ni(II) and $\mathrm{Pb}$ (II) from aqueous solution by dried biomass of Aspergillus niger: application of response surface methodology to the optimization of process parameters, Clean-Soil, Air, Water, 37(10), 776-786.

Amini M., Younesi H. and Bahramifar N. (2009), Biosorption of nickel (II) from aqueous solution by Aspergillus niger: response surface methodology and isotherm study, Chemosphere, 75(11), 1483-1491.

Azila Y., Mashitah M.D. and Bhatia S. (2008), Process optimization studies of lead $(\mathrm{Pb}(\mathrm{II}))$ biosorption onto immobilized cells of Pycnoporus sanguineus using response surface methodology, Bioresource Technology, 99, 85498552.

Azimi A., Azari M. and Rezakazemi M., et al. (2017), Removal of heavy metals from industrial wastewaters: A review, ChemBioEng Reviews, 4, 37-59.

Balci B., Keskinkan O. and Avci M. (2011), Use of BDST and ANN model for prediction of dye adsorption efficiency of Eucalyptus camaldulensis barks in fixed-bed system, Expert Systems With Applications, 38, 949-956.

Bayramoglu G. and Arica M.Y. (2011), Synthesis of $\mathrm{Cr}(\mathrm{VI})$ imprinted poly(4-vinyl pyridine-co-hydroxyethyl methacrylate) particles: Its adsorption propensity to $\mathrm{Cr}(\mathrm{VI})$, Journal of Hazardous Materials, 187(1-3), 213-221.

Bingol D., Hercan M., Elevli S. and Kılıc E. (2012), Comparison of the results of response surface methodology and artificial neural network for the biosorption of lead using black cumin, Bioresource Technology, 112, 111-115.

Brown M. and Margolis S. (2012), Lead in drinking water and human blood lead levels in the United States, Morbidity and Mortality Weekly Report, 61(04), 1-9.

Davies K.M., Mercer J.F., Chen N. and Double K.L. (2016), Copper dyshomoeostasis in Parkinson's disease: implications for pathogenesis and indications for novel therapeutics, Clinical Science, 130, 565-574.

Fang J., Gu Z., Gang D., Liu C., Ilton E.S. and Deng B., et al.(2007), Environmental Science \& Technology, 41, 4748-4753.

Fountouli T.V. and Chrysikopoulos C.V. (2018), Adsorption and thermodynamics of pharmaceuticals, acyclovir and fluconazole, onto quartz sand under static and dynamic conditions, Environmental Engineering Science.

Guo J. and Lua A.C. (2000), Textural characterization of activated carbons prepared from oil-palm stones pretreated with various impregnating agents, Journal of Porous Materials, 7(4), 491-497.

Hegazy E.H., Kamal H., Khalifa N.A. and Mahmoud G.A. (2001), Separation and extraction of some heavy and toxic metal ion from their wastes by grafted membrane, Journal of Applied Polymer Science, 81, 849-860.

Kose T.E., Demiral H. and Ozturk N. (2011), Adsorption of boron from aqueous solutions using activated carbon prepared from olive bagasse, Desalination and Water Treatment, 29, 110-118.

Li W., Peng J., Zhang L., Yang K., Xia H., Zhang S. and Guo S.H. (2009), Preparation of activated carbon from coconut shell 
chars in pilot-scale microwave heating equipment at $60 \mathrm{~kW}$, Journal of Waste Management, 29(2), 756-60.

Li Z., Huang X.X., Sun C.L., Chen X.Y., Hu J.B., Stein A. and Tang B.H.J. (2017), Thin-film electrode based on zeolitic imidazolate frameworks (ZIF-8 and ZIF-67) with ultra-stable performance as a lithium-ion battery anode, Journal of Materials Science, 52, 3979-3991.

Liu B., Lv X., Meng X., Yu G. and Wang D. (2013), Removal of $\mathrm{Pb}$ (II) from aqueous solution using dithiocarbamate modified chitosan beads with $\mathrm{Pb}(\mathrm{II})$ as imprinted ions, Chemical Engineering Journal, 220, 412-419.

Liu X.-Y., Huang M. and Ma H.-L., et al. (2107), ZIF-Derived Nitrogen-doped Porous Carbons as Highly Efficient Adsorbents for Removal of Organic Compounds from Wastewater, Chemical Engineering Journal, 323,502-511.

Niu Y., Li K., Ying D., Wang Y. and Jia J. (2017), Novel recyclable adsorbent for the removal of copper(II) and lead(II) from aqueous solution, Bioresource Technology, 229, 63-68.

Shahrak M.N., Ghahramaninezhad M. and Eydifarash M. (2017), Zeolitic imidazolate framework-8 for efficient adsorption and removal of $\mathrm{Cr}(\mathrm{VI})$ ions from aqueous solution, Environmental Science and Pollution Research, 24, 9624-9634.

Sotirelis N.P. and Chrysikopoulos C.V. (2015), Interaction between graphene oxide nanoparticles and quartz sand, Environmental Science \& Technology, 49(22), 13413-13421.

Tong S., von Schirnding Y.E. and Prapamontol T. (2000), Environmental lead exposure: a public health problem of global dimensions, Bulletin of the World Health Organization, 78(9), 1068-1077.

Vasiliadou I.A. and Chrysikopoulos C.V. (2011), Cotransport of Pseudomonas putida and kaolinite particles through watersaturated columns packed with glass beads, Water Resources Research, 47(2).

Venkatesh M.S. and Raghavan G.S.V. (2004), An overview of microwave processing and dielectric properties of agri-food materials, Biosystems Engineering, 88(1), 41-18.

Zhu Y.-L., Han X.-J. and Guo X.-Y. (2010), Preparation of a Carbon-Based Solid Acid Catalyst by Sulfonating Activated Carbon in a Chemical Reduction Process, Molecules, 15, 7188-7196. 